\title{
Abnormalities of Immune Regulation in Human Immunodeficiency Virus Infection
}

\author{
GENE M. SHEARER AND MARIO CLERICI \\ Experimental Immunology Branch, National Cancer Institute, National Institutes of Health, \\ Bethesda, Maryland 20892
}

\begin{abstract}
The severe depletion of CD4+ T cells is the most obvious and dramatic immunologic event that occurs in individuals infected with the human immunodeficiency virus (HIV) type 1 during development to AIDS. Nevertheless, a complex and sequential pattern of loss of Thelper cell (TH) function can occur years before development of AIDS symptoms. Such suppression could be due to immunosuppressive factors that are either products of $\mathrm{HIV}$, such as gp120 and tat, or HIV-induced immunoregulatory cytokines such as transforming growth factor $-\beta$ and IL-10. Recent data suggest that multiple and independent immunosuppressive factors, including gp120-induced suppression and IL-10, are responsible for the loss of TH function seen in HIV-infected individuals before development of symptoms. The same TH functional abnormalities observed in adult patients are also seen in pediatric cases. Pediatric cases of HIV infection present some unique problems, however, in that one needs to be able to distinguish between HIV-induced suppression of TH function and the absence of TH function that is due to lack of maturation or immunologic priming. (Pediatr Res 33 (Suppl): S71S75, 1993)
\end{abstract}

\section{Abbreviations}

ALLO, HLA alloantigen

APC, antigen-presenting cell

AZT, azidothymidine (zidovudine)

CBL, cord blood leukocyte

ddI, dideoxyinosine

FLU, influenza A virus

HIV, human immunodeficiency virus

PHA, phytohemagglutinin

PBL, peripheral blood leukocyte

r, recombinant

REC, recall antigen

TH, T-helper cell

AIDS is characterized by a severe depletion of CD4+ T lymphocytes, susceptibility to opportunistic infections, hypergammaglobulinemia, and, in some cases, the appearance of lymphomas or generalized Kaposi's sarcoma $(1,2)$. The most obvious and dramatic immunologic event that occurs during the development of AIDS is the well-known decline in the number of CD4+ T cells, which has resulted in the use of this parameter (often referred to as "CD4 count") as the most important marker for assessing AIDS progression and therapeutic efficacy of antiretroviral drugs $(3,4)$. There is no doubt that CD4 counts provide

Correspondence: Gene M. Shearer, Ph.D., Experimental Immunology Branch, National Cancer Institute, Building 10, Room 4B17, National Institutes of Health, Bethesda, MD 20892. an important indicator of susceptibility to opportunistic agents, and critically low numbers of CD4+ cells $\left(<50 / \mathrm{mm}^{3}\right)$ have been shown to be predictive for death in AIDS patients (5). Thus, to date, the major emphasis has been placed on quantitative aspects of CD4 cells.

The mechanism(s) responsible for the decline in CD4 counts in individuals infected with HIV are still unresolved, although several proposals have been made to account for CD4 T-cell depletion. These include a direct cytopathic effect of HIV; cell fusion and the formation of giant multinucleated cells; cytolysis of infected, or gp120-coated, CD4+ cells; autoimmunity; and programmed cell death or apoptosis (6-14).

However, despite the ultimate decline in CD4 counts in progression to AIDS, loss of TH function can occur years before CD4 counts drop to critical levels and AIDS symptoms appear (15-17). This loss in TH function is complex and sequential such that $\mathrm{TH}$ responses to REC, e.g. FLU and tetanus toxoid, occur before the loss of TH function to ALLO, which appears before the loss of response to the T-cell mitogen, PHA (16). Although this sequential loss in TH function was most extensively studied in adults, a similar pattern of decline in $\mathrm{TH}$ function has been reported in HIV-infected children (18). In the above studies, TH function was measured by ${ }^{3} \mathrm{H}$-thymidine incorporation and/or IL-2 production. Similar results have been reported in which the proliferation of $\mathrm{T}$ cells stimulated with soluble anti-CD3 was lost before proliferation to insolubilized anti-CD3 (15). The loss of TH function to REC is predictive for a decline in CD4 counts in asymptomatic, HIV-infected (HIV+) adults but does not appear to be associated with increased susceptibility to opportunistic infections (19). However, in pediatric patients with AIDS symptoms, the absence of TH function to REC is associated with susceptibility to bacterial infections, and the loss of responsiveness to PHA is associated with susceptibility to opportunistic infections (18). Although these early examples of TH dysregulation are not currently used as part of either the Centers for Disease Control or the Walter Reed staging criteria, they do, nevertheless, herald events predictive for or associated with AIDS. Thus, we consider changes in T-cell function to be relevant for AIDS development and instructive for understanding some of the earliest events of HIV-induced immune dysregulation.

\section{MECHANISMS FOR LOSS OF TH FUNCTION}

The loss of $\mathrm{TH}$ function without critical depletion of CD4+ cells (for example, $>400 \mathrm{CD} 4+$ cells $/ \mathrm{mm}^{3}$ ) could be due to at least two different effects: 1) loss of accessory or APC function necessary for activating TH cells, or 2) loss of TH function by immunosuppressive or inhibitory factors. Concerning the first possibility, we did not detect APC defects in the antigen-presenting function of PBL from HIV+ individuals but did detect APC defects in approximately two thirds of patients with AIDS (20). Furthermore, we have costimulated TH with APC by using PBL from monozygotic twins, one who was HIV+ and unresponsive to REC and the other who was uninfected (HIV-) and responsive 
to REC. TH from the HIV-individual plus APC from the HIV+ individual responded to REC. In contrast, TH from the HIV+ donor plus APC from the HIV- donor did not respond to REC (21). The results of the above experiments indicate that the early defect is not attributable to a defect in antigen presentation but is due to some intrinsic defect in TH function (Fig. 1).

Several laboratories have reported that PBL from AIDS patients can suppress the T-cell responses of PBL from HIVdonors (22-25), and one laboratory has demonstrated the presence of a suppressive factor (23). By coculturing PBL from the $\mathrm{HIV}+$ and HIV- monozygotic twins noted above (Fig. 2), as well as samples of cryopreserved PBL from the same individual taken before seroconversion and after the development of AIDS, we demonstrated suppression of TH function to REC, but not to ALLO or PHA (26). The suppressive effect was mediated by CD8+ but not by CD4+ T cells, and a factor that also selectively suppressed REC-specific TH responses was produced by shortterm culture of CD8+ but not CD4+ cells from the patients. The suppressive factor was found not to be HIV. It is noteworthy that two of the AIDS patients whose CD8+ cells produced the

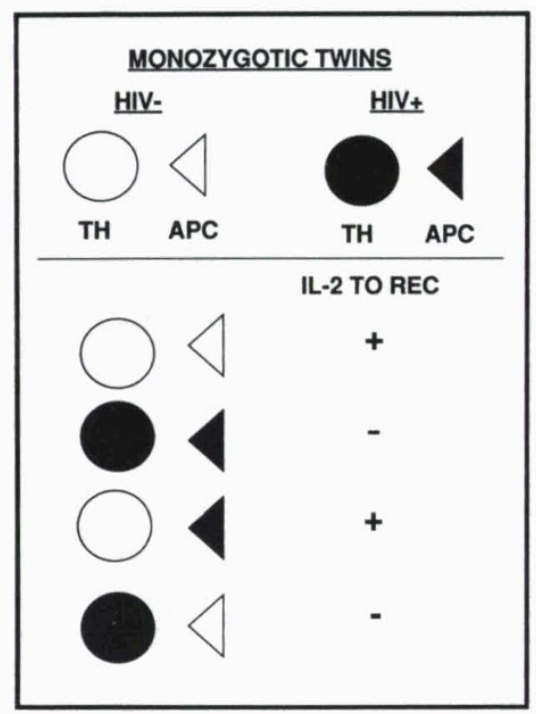

Fig. 1. Schematic diagram summarizing results of experiments using TH and APC from a pair of monozygotic twins, one who was HIVinfected and one who was uninfected. APC were irradiated with 5000 rad.

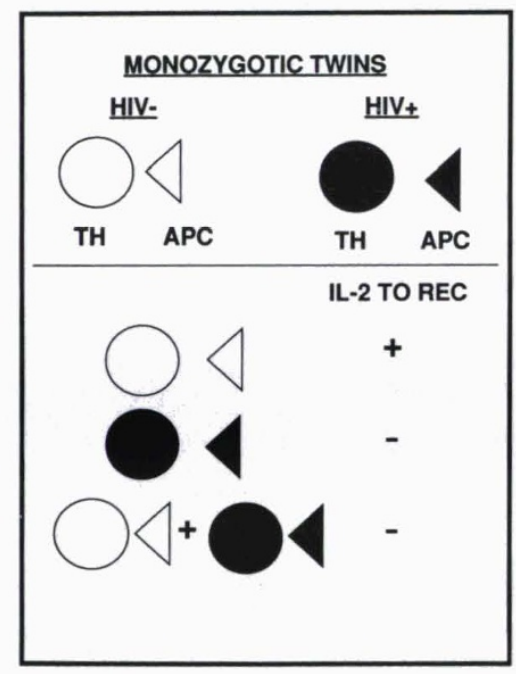

Fig. 2. Schematic diagram summarizing results of experiments demonstrating immunologic suppression by coculture of PBL from HIVinfected and uninfected monozygotic twins. suppressive factor were on antiretroviral drug therapy. Thus, despite AIDS therapy, these patients produced a factor that suppressed TH function to REC. It is of interest that AIDS patients whose lack of TH function is attributed to CD4+ T-cell depletion are likely to also exhibit a defect (suppression) that is not due to TH depletion. Finally, it should be noted that one of the pairs of discordant monozygotic twins whom we studied was $5 \mathrm{y}$ of age (26). This indicates that suppressive factors can also contribute to the immune deficiency seen in pediatric cases of AIDS.

Identification of the inhibitory factor(s) has not yet been made, but several candidates exist, including products of HIV such as gp120 (27-29) and tat (30) and immunoregulatory cytokines such as transforming growth factor- $\beta$ (31) (Table 1) and IL-10 $(32,33)$. It is also possible that HIV-induced antibodies block the interaction between TH and APC, e.g. the gp41 antibody that cross-reacts with nonpolymorphic HLA class II determinants (34). Based on preliminary results, we consider it likely that multiple factors contribute to the inhibition of efficient T-cell activation in HIV+ individuals. For example, it is probable that IL-10, a cross-regulatory cytokine produced by the TH2 functional subset of $\mathrm{T}$ cells and monocytes in humans $(35,36)$ downregulates $\mathrm{TH} 1$ cells, which characteristically produce interferon$\gamma$ and IL-2. In the process, IL-4, IL-5, and IL-6 (cytokines that augment B cell responses), as well as IL-10, are produced by $\mathrm{TH} 2$ cells. Thus, we have observed in HIV+ individuals that the down-regulation of IL-2 production that we have consistently observed in hundreds of cases (16) is accompanied by increased production of IL-4 (37). At a second level, it is probable that a product of HIV itself will be shown to be responsible for immune suppression in HIV+ individuals. Several laboratories have reported that the gp120 envelope protein of HIV can suppress in vitro-generated T-cell responses of PBL from HIV- individuals $(27-30)$. Because the gp120 envelope protein is used by the virus to bind the CD4 molecule on CD4+ cells, it is possible that free gp120 would also bind to CD4 on T cells, thereby preventing their efficient activation. In fact, we have been able to block the in vitro inhibitory effect of gp 120 with $\mathrm{rCD} 4-\mathrm{IgG}$, an agent that has been used in AIDS therapeutic trials (see below). Finally, the suppressive factor described above that is produced by CD8+ cells from HIV+ individuals could represent a third type of suppressive phenomenon. It is possible that this factor is the same as that described by Walker et al. (36), which inhibits HIV replication in vitro and is produced by CD8+ cells. In conclusion, there are a number of factors, some products of cells and some products of HIV itself, that can induce immune suppression in experimental systems and could therefore contribute to the immune deficiency that is independent of CD4+ cell depletion in both asymptomatic and symptomatic HIV-infected individuals.

\section{THERAPY-INDUCED IMPROVED TH FUNCTION}

A number of protocols have been initiated to test the effects of antiretroviral therapy in both asymptomatic patients and patients with AIDS (38-42). The surrogate markers used to test the efficacy of AZT (zidovudine), ddI, and rCD4-IgG include increased CD4 counts and reduced serum levels of p24 antigen and of $\beta 2$ microglobulin (38-43). By these markers, as well as increased life-span and improved quality of life, it has been concluded that AZT and ddI, but not rCD4-IgG, are efficacious therapeutic agents. However, only some patients on therapy showed an increase in CD4 counts. Based on the observations that loss of TH can be independent of CD4 counts, we considered the possibility that improved $\mathrm{TH}$ function could occur in patients on therapeutic trials who do not necessarily show increased CD4 counts. Thus, we have tested: 1 ) both asymptomatic and symptomatic adult patients on AZT, 2) symptomatic pediatric patients on ddI, and 3) symptomatic adult patients on rCD4-IgG (44, 45). We observed improved in vitro TH function in: 1) $75 \%$ of both asymptomatic and symptomatic patients on AZT, 2) more 
Table 1. Factors in HIV+ individuals that could be responsible for inhibition of TH immune function and source, site of action, and possible therapeutic strategy for such factors

\begin{tabular}{clcl}
\hline Blocking factor & Factor produced by & Cell type affected & Suppressive effect inhibited by \\
\hline gp120 & HIV & TH & Recombinant CD4-IgG \\
IL-10 & Monocytes, TH2 cells & TH & Antibodies to TH2 cytokines (anti-IL-10; anti-IL-4) \\
Anti-gp41 & B cells & APC & \\
\hline
\end{tabular}

than $50 \%$ of the pediatric patients on ddI, and 3) $90 \%$ of the patients on rCD4-IgG. Improved TH function was correlated with resistance to opportunistic infections in pediatric patients on ddI therapy $(44,45)$. In all three studies, improved TH was observed independently of increased CD4 counts. The incidence of improved TH function in asymptomatic HIV+ patients not on therapy was less than $7 \%$. In these three studies, improved $\mathrm{TH}$ function was more readily observed for responses to ALLO and PHA than for responses to REC in asymptomatic patients. In patients with AIDS, improved TH function was detected for responses to ALLO and PHA, but not to REC. This is probably because symptomatic patients have reduced CD4 counts, and TH responses to ALLO and PHA can be mediated by CD8+ as well as CD4+ cells (43). The data suggest that: 1) suppressive factors, the effects of which can be reversed by therapy, contribute to the immune deficiency in these patients, and 2) CD8+ TH cells are also susceptible to suppression. It is noteworthy that the dramatic improvement in TH function that we observed by in vitro testing for $\mathrm{TH}$ function of the patients on $\mathrm{rCD} 4-\mathrm{IgG}$ did not agree with the conclusions that these patients showed no evidence of therapeutic efficacy. The reason for this dichotomy is not known, but it could reflect that: 1) our TH test is not relevant for improved status of AIDS patients, or 2) the parameters currently used for assessing therapeutic efficacy are not adequate and fail to detect some factors that could be relevant for the patient's status. Our results raise the possibility that qualitative as well as quantitative immunologic parameters should be included in assessing the efficacy of therapeutic regimens for AIDS.

\section{TH STUDIES RELEVANT FOR PEDIATRIC IMMUNODEFICIENCY STATES}

We have observed that the same functional defects that are detected in asymptomatic and symptomatic adults infected with HIV are also observed in children infected with HIV who have AIDS symptoms (18). Thus, pediatric patients have been observed whose PBL: 1) fail to respond to REC but respond to ALLO and PHA, 2) fail to respond to REC and ALLO, but respond to PHA, and 3) fail to respond to all three stimuli. The higher incidence of more severe $\mathrm{TH}$ immune defects in pediatric patients than in the adult patients may reflect: 1 ) the fact that most of the children we studied were symptomatic, whereas most of the adults were asymptomatic, and/or 2) the possibility that the immune system of children may be weaker than that of adults due to lack of maturation or of adequate immunologic exposure and priming. Thus, before evaluating TH functional immune parameters in HIV-infected infants, one may need to reexamine $\mathrm{TH}$ function in healthy newborns and infants.

Several studies have been performed to evaluate the ability of CBL from HIV- deliveries to produce cytokinesc in response to mitogenic stimuli (46-49). It was found that CBL express IL-2 receptors and produce near adult levels of IL-2 when stimulated with mitogens but are defective for interferon- $\gamma$ production (4649). We have observed that $\mathrm{TH}$ function generated by leukocytes from infants of different ages is very different in response to REC, ALLO, and PHA (Clerici M, unpublished data). Thus, TH function assessed by IL-2 production or by ${ }^{3} \mathrm{H}$-thymidine incorporation in response to the REC FLU was negative to REC by CBL and by PBL from infants up to 24 mo of age. PBL from children older than 24 mo responded to REC, as did PBL from adults. CBL and PBL from infants and children of all ages responded as well as did PBL from adults to both ALLO and PHA.

The most interesting results were those obtained in response to adult allogeneic leukocytes depleted of APC (ALLO-APC). In this experiment, the responding PBL not only provide the helper cells but are also required to provide accessory or antigenpresenting function, and the 5000 rad-irradiated adult allogeneic stimulator cells provide only the alloantigens. Our results indicate that: 1) CBL respond to ALLO-APC and ALLO; 2) PBL from infants between 6 and 13 mo of age do not respond to ALLOAPC but do respond to ALLO; and 3) children older than 14 mo, as well as adults, respond to ALLO-APC and ALLO. Although neither infants' PBL nor CBL respond to REC, possibly due to lack of sufficient priming, the most striking finding is that CBL but not PBL from 6- to 13-mo-old infants respond to ALLO-APC. It appears that CBL are more developed to respond to an antigen for which priming is not required but for which autologous antigen presentation (ALLO-APC) is required than are PBL from infants between 6 and 13 mo of age. We have attributed this to an age-dependent defect of antigen-presenting function maturation, in which both TH and APC of CBL are relatively mature, possibly due to exposure to maternal cytokines in utero. This state of maturation is temporary; it is lost by $6 \mathrm{mo}$ of age and not regained by normal developmental mechanisms until 13 mo of age. We also consider that this defect, which is lost after birth, is attributable to an APC defect and not to a defect in $\mathrm{TH}$ function. Our results raise the possibility that newborns will exhibit more mature TH potential than will infants between 6 and 13 mo of age. These findings from studies performed in healthy infants need to be taken into consideration in studies aimed at assessing T-cell function in primary and acquired immune deficiency states. Thus, if CBL are functionally more developed than the PBL of infants less than 13 mo of age, and if such temporary development is the result of the influence of maternal cytokines in utero, then analysis of cellular immune function could be misleading if tested only at birth or soon thereafter (when maternal cytokines could still exert an influence) in infants suspected of primary or acquired immune deficient states. The above discrepancy between the functional maturation of CBL and infant PBL (from 6 to 13 mo of age) also raises the possibility of efficient immunization for T-cell immunity in utero or at birth compared with immunization of 6- to 13-mo-old infants. Such consideration could be important in congenital infections by cytomegalovirus, Toxoplasma, or HIV.

\section{REFERENCES}

1. Fauci AS 1988 The human immunodeficiency virus: infectivity and mechanisms of pathogenesis. Science 239:617-623

2. Kopelman RG, Zolla-Pazner S 1988 Association of human immunodeficiency virus infection and autoimmune phenomena. Am J Med 84:82-94

3. Spickett GP, Dalgleish AG 1988 Cellular immunology of HIV infection. Clin Exp Immunol 71:1-7

4. Yarchoan R, Broder S 1989 Immunology of HIV infection. In: Paul WE (ed) Fundamental Immunology, 2nd Ed. Raven Press, New York, pp 1059-1079

5. Yarchoan R, Venzon DJ, Pluda JM, Lietzau J, Wyvill KM, Tsiatis AA, Steinberg SM, Broder S 1991 CD4 count and the risk for death in patients infected with HIV receiving antiretroviral therapy. Ann Intern Med 115:184189

6. Lifson JD, Feiberg MB, Reyes GR, Rabin L, Banapour B, Chakrabarti S, Moss B, Wong-Staal F, Steimer KS, Engleman EG 1986 Induction of CD4dependent cell fusion by the HTLV-III/LAV envelope glycoprotein. Nature 323:725-728

7. Siliciano RF, Lawton T, Knall C, Karr RW, Berman P, Gregory T, Reinherz EL 1988 Analysis of host-virus interaction in AIDS with anti gp120 T cell clones: effects of HIV sequence variation and a mechanism for CD4+ cell depletion. Cell 54:561-575 
8. Germain RN 1988 Antigen processing and CD4+ T cell depletion in AIDS Cell 54:441-444

9. Ljunggren K, Bottiger B, Biberfeld G, Karlson A, Fenyo EM, Jondal M 1987 Antibody dependent cellular cytotoxicity inducing antibodies against human immunodeficiency virus: presence at different clinical stages. J Immunol 139:2458-2463

10. Ojo-Amaize EA, Nishanian P, Kieth DE, Houghton RL, Heitjan DF, Fahey JL, Giorgi JV 1987 Antibodies to human immunodeficiency virus in human sera induce cell-mediated lysis of human immunodeficiency virus infected cells. J Immunol 139:2458-2463

11. Stricker RB, McHugh TM, Moody DJ, Morrow DP, Stites MA, Shuman MA, Levy JA 1987 An AIDS-related cytotoxic autoantibody reacts with a specific antigen on stimulated CD4+ T cells. Nature 327:710-713

12. Zinkernagel RM 1988 Virus-triggered AIDS: a T-cell-mediated immunopathology? Immunol Today 9:370-372

13. Via CS, Morse III HC, Shearer GM 1990 Altered immunoregulation and autoimmune aspects of HIV infection: relevant murine models. Immunol Today 11:250-255

14. Miedema F, Petit AJ, Terpstra FG, Schattenkerk JK, deWolf F, Al BJ, Roos M, Lange JM, Danner SA, Goudsmit J, Schellekens PT 1988 Immunological abnormalities in human immunodeficiency virus (HIV)-infected asymptomatic homosexual men: HIV affects the immune system before CD4+ T helper cell depletion occurs. J Clin Invest 82:1908-1914

15. Clerici M, Stocks NI, Zajac RA, Boswell RN, Lucey DR, Via CS, Shearer GM 1989 Detection of three distinct patterns of T helper cell dysfunction in asymptomatic, human immunodeficiency virus-seropositive patients. J Clin Invest 84:1892-1899

16. Petersen J, Church J, Gomperts E, Parkman R 1989 Lymphocyte phenotype does not predict immune function in pediatric patients infected with human immunodeficiency virus type 1. J Pediatr 115:944-948

17. Roilides E, Clerici M, DePalma L, Rubin M, Pizzo PA, Shearer GM 1991 Helper T-cell responses in children infected with human immunodeficiency virus type 1. J Pediatr 118:724-730

18. Lucey DR, Melcher GP, Hendrix CW, Zajac RA, Goetz DW, Butzin CA, Clerici M, Warner RD, Abbadessa S, Hall S, Jose R, Woolford B, Miller S, Stocks NI, Salinas CM, Wolfe WH, Shearer GM, Boswell RN 1991 Human immunodeficiency infection in the US Air Force: seroconversion, clinica staging, and assessment of a $\mathrm{T}$ helper cell functional assay to predict change in CD4+ T cell counts. $J$ Infect Dis 164:631-637

19. Clerici M, Lucey DR, Zajac RA, Boswell RN, Gebel HM, Takahashi H, Berzofsky JA, Shearer GM 1991 Detection of cytotoxic T lymphocytes specific for synthetic peptides of gpl60 in HIV-seropositive individuals. J Immunol 146:2214-2219

20. Laurence J, Gottlieb A, Kunkel HG 1983 Soluble suppressor factors in patients with acquired immunodeficiency syndrome and its prodome: elaboration in vitro by T-lymphocyte-adherent cell interactions. J Clin Invest 72:20722081

21. Clerici M, Via CS, Lucey DR, Roilides E, Pizzo PA, Shearer GM 199 Functional dichotomy of CD4+ T helper lymphocytes in asymptomatic human immunodeficiency virus infection. Eur J Immunol 21:665-670

22. Laurence J, Mayer L 1984 Immunoregulatory lymphokines of $\mathrm{T}$ hybridomas from AIDS patients: constitutive and inducible suppressor factors. Science 225:66-69

23. Hoffman B, Odum N, Jakobsen BK, Dickmeiss E, Plata P, Ryder LP, Pedersen C, Matiesen L, Bygbjeng I, Faber V, Sueffard H 1986 Immunological studies in AIDS. II. Active suppression of intrinsic defect investigated by mixing AIDS cells with HLA-DR identical normal cells. Scand J Immunol 23:669678

24. Joly P, Guillon JM, Mayaud C, Plata F, Theodorou I, Denis M, Debre P, Autrien B 1989 Cell-mediated suppression of HIV-specific cytotoxic T lymphocytes. J Immunol 143:2193-2201

25. Weinhold KJ, Lyerly HK, Stanley SD, Austin AA, Mathews TJ 1989 HIV-1 gp120-mediated immune suppression and lymphocyte destruction in the absence of viral infection. J Immunol 142:3091-3097

26. Clerici M, Roilides E, Via CA, Pizzo PA, Shearer GM 1992 A factor from CD8 cells of human immunodeficiency virus-infected patients suppresses HLA self-restricted T helper cell responses. Proc Natl Acad Sci USA 89:84248428

27. Diamond DC, Sleckman BP, Gregory T, Lasky LA, Greinstein JL, Burakoff SJ 1988 Inhibition of CD4+ cell function by the envelope protein gp120. J Immunol 141:3715-3717

28. Chirmule N, Kalyanaraman VS, Oyaizu N, Slade HB, Pahwa S 1990 Inhibition of functional properties of tetanus antigen-specific T-cell clones by envelope glycoprotein gp120 of human immunodeficiency virus. Blood 75:152-159

29. Rosenstein Y, Burakoff SJ, Herrman SH 1990 HIV-gp120 can block CD4class II MHC-mediated adhesion. J Immunol 144:526-531

30. Viscidi RP, Mayur K, Lederman HM, Frankel RD 1989 Inhibition of antigeninduced lymphocyte proliferation by tat protein from HIV-1. Science 246:1606-1608

31. Kekow J, Wachsman W, McCutchan JA, Cronin M, Carson DA, Lotzz M 1990 Transforming growth factor $\beta$ and noncytopathic mechanisms of immunodeficiency in human immunodeficiency virus infection. Proc Natl Acad Sci USA 87:8321-8325

32. Shearer GM, Clerici M 1992 T helper cell immune dysfunction in asymptomatic, HIV-1-seropositive individuals: the role of TH1-TH2 cross regulation. Prog Chem Immunol 54:21-43

33. Golding H, Shearer GM, Hillman K, Lucus P, Manischewitz J, Zajac RA,
Clerici M, Gress RE, Boswell RN, Golding B 1989 Common epitope in human immunodeficiency virus (HIV) 1 -gp41 and HLA class II elicits immunosuppressive autoantibodies capable of contributing to immune dysfunction in HIV 1-infected individuals. J Clin Invest 83:1430-1435

34. de Waal Malefyt R, Haanen J, Spits H, Roncarolo M-G, te Velde A, Figdor C, Johnson K, Kastelein R, Yssel H, de Vries JE 1991 Interleukin 10 (IL-10) and viral IL-10 strongly reduce antigen-specific human $\mathrm{T}$ cell proliferation by diminishing the antigen-presenting capacity of monocytes via downregulation of class II major histocompatibility complex expression. J Exp Med 174:915-924

35. de Waal Malefyt R, Alrams J, Bennett B, Figdor CG, de Vries JE 1991 Interleukin 10 (IL-10) inhibits cytokine synthesis by human monocytes: an autoregulatory role of IL-10 produced by monocytes. J Exp Med 174:12091220

36. Walker CM, Moody DJ, Stites DP, Levy JA 1986 CD8+ lymphocytes can control HIV infection in vitro by suppressing virus replication. Science 234:1563-1566

37. Clerici M, Hakim FT, Venzon DJ, Blatt S, Hendrix CW, Wynn TA, Shearer GM 1992 Changes in interleukin-2 and interleukin-4 production in asymptomatic, HIV-seropositive individuals. J Clin Invest (in presss)

38. Volberding P, Lagakos SW, Koch MA, Pettinelli C, Myers MW, Booth DK, Balfour Jr HH, Reichman RC, Bartlett JA, Hirsch MS 1990 Zidovudine in asymptomatic human immunodeficiency virus infection: A controlled trial in persons with fewer than $500 \mathrm{CD} 4$-positive cells per cubic millimeter. The AIDS Clinical Trials Group of the National Institute of Allergy and Infectious Diseases. N Engl J Med 322:941-949

39. Lambert JS, Seidlin M, Reichman RC, Plank CS, Laverty M, Morse GD, Knupp C, McLaren C, Pettinelli C, Valentine FT, Dolin R 1990 2',3'dideoxyinosine (ddI) in patients with the acquired immunodeficiency syndrome or AIDS-related complex: a phase I trial. N Engl J Med 322:13331340

40. Cooley TP, Kunches LM, Saunders CA, Ritter JK, Perkins CJ, McLaren C, McCaffrey RP, Liebman HA 1990 Once-daily administration of $2^{\prime}, 3^{\prime}$ dideoxyinosine (ddI) in patients with the acquired immunodeficiency syndrome or AIDS-related complex: results of a phase I trial. N Engl J Med 322:1340-1345

41. Merrigen TC, Skowron G, Bozzette SA, Richman D, Utamchandani R, Fischl M, Schooley R, Hirsch M, Soo W, Pettinelli C, Schaumberg H 1989 The ddC study group of the AIDS clinical trials group: circulating p24 antigen levels and responses to dideoxycitidine in human immunodeficiency virus (HIV) infections. A phase I and II study. Ann Intern Med 110:189-194

42. Yarchoan R, Pluda JM, Thomas RV, Mitsuya H, Brouwers P, Wyvill KM, Hartman N, Johns DG, Broder S 1990 Long-term toxicity/activity profile of $2^{\prime} 3^{\prime}$-dideoxyinosine in AIDS or AIDS-related complex. Lancet 336:526529

43. Via CS, Tsokos GC, Stocks NI, Clerici M, Shearer GM 1990 Human in vitro allogeneic responses: demonstration of three pathways of $\mathrm{T}$ helper cell activation. J Immunol 144:2524-2528

44. Clerici M, Landay AL, Kessler HA, Phair JP, Venzon DJ, Hendrix CW, Lucey DR, Shearer GM 1992 Reconstitution of long-term T helper cell function after zidovudine therapy in human immunodeficiency virus-infected patients. J Infect Dis 166:723-730

45. Clerici M, Roilides E, Butler KM, De Palma L, Venzon DJ, Shearer GM, Pizzo PA 1992 Changes in T helper cell function in human immunodeficiency virus-infected children during dianosine therapy as a measure of antiretroviral activity. Blood (in press)

46. Bryson YJ, Winter HS, Gard SE, Fischer TJ, Stiehm ER 1980 Deficiency immune interferon production by leukocytes of normal newborns. Cell Immunol 55:191-200

47. Wakasugi N, Virelizier J-L 1985 Defective IFN- $\gamma$ production in the human neonate. I. Dysregulation rather than intrinsic abnormality. J Immunol 134:167-171

48. Wilson CB 1991 The ontogeny of T lymphocyte maturation and function. J Pediatr 118:S4-S9

49. Lewis DB, Yu CC, Meyer J, English BK, Kahn SJ, Wilson CB 1991 Cellular and molecular mechanisms for reduced interleukin 4 and interferon- $\gamma$ production by neonatal T cells. J Clin Invest 87:194-202

\section{FLOOR DISCUSSION}

Dr. Schwartz: We and others have reported that it appears naive responders can respond to HIV peptides. We have demonstrated this with envelope peptides with HIV- individuals, so that you may be seeing a de novo response without necessarily the education of these cells by contact with HIV peptides. We think that the peptides have a direct mitogenic activity, particularly, in our hands, peptides from gp41.

I would also like to make a comment as a corollary to your observations with IL-2. We have recently reported that with a fusion peptide, an envelope gag peptide that predominates with gp41 residues, we have been able to demonstrate, at a transcriptional level, specific down-regulation/inhibition of IL-2 gene expression as well as IFN- $\gamma$ receptor gene expression. That fits very nicely with the data that you have described, but I would 
be careful about the issue of specific responses to some of these envelope peptides because they do seem to stimulate even naive cells, which are PCR (polymerase chain reaction) negative.

Dr. Shearer: That is an interesting comment. We went into a study of the HIV-specific responses in cord bloods because we believe that these are going to be significant. We have studied HIV-seronegative individuals, both low risk and high risk. So far, we have followed 155 low-risk adults, using Dr. Jay Berzofsky's peptides and Dr. Clerici's assay. We have found 10 of 155 $(6.5 \%)$ who show either proliferative or IL-2 responses to this series of HIV peptides. In contrast, in testing high-risk homosexual men from Los Angeles, we have found five out of five who were positive by this T-cell assay and who were seronegative and PCR negative. Our findings were similar in a different at-risk individual who was initially both seronegative and PCR negative. Approximately $50 \%$ of seronegative gay men have tested positive to these peptides. Approximately $40 \%$ of i.v. drug abusers have been positive by our T-cell test, despite their being seronegative. We are also finding seronegative health care workers who have had needle sticks who show T-cell responses in our assay. In our experience, we are finding that approximately $7 \%$ of low-risk individuals show this activity. In contrast, known high-risk individuals are running up around 40 to $50 \%$. We went into the pediatric HIV study because of our extensive experience in HIVspecific TH responses. Whether they are infected or not, I do not know. What we can say is, it looks as if these exposed individuals have had an immunologic exposure that would indicate they have been primed. We have no reason to think that these at-risk, exposed individuals are naive in their exposure to HIV. A test of HIV seronegativity does not prove lack of exposure.

Dr. Gupta: It appears that loss of the function of the TH to REC might be more at the level of the responder cell rather than a suppression phenomenon. We published a paper in January 1983 in the Journal of Clinical Investigation on Kaposi's sarcoma with a normal CD4 cell count in which autologous immune responses were depressed. When we depleted the CD8+ cells, those cells still did not respond. In a later publication, we reported that if you add IL-2 you can reconstitute that response. So in those cases, perhaps the lack of response is because of the lack of a responder population or production of IL-2 rather than a suppressor phenomenon. Secondly, I think we should be really cautious when discussing the CD45 RA as a memory cell. We have 14 MVP cell lines that respond to MVP and express both the stable CD45 RO and RA, so those markers are not without the ability to distinguish between memory and naive cells. Lastly, do you have any idea as to the mechanism of AZT-induced restoration of those immune responses that you showed?

Dr. Shearer: No, we have not resolved the mechanisms. But it turns out that in asymptomatic individuals who are on AZT we can see at least a partial restoration of T-helper function to REC, as well as a more complete restoration of responses to ALLO and PHA. When one goes to AIDS patients who have depleted CD4 cell numbers, we never see restoration of response to REC, which we would expect, based on low CD4 counts. I think these assays are measuring factors or soluble materials, perhaps products of HIV or cytokines or suppressive factors, that may be modulated by AZT therapy. However, as I pointed out, that one child who was on ddI still was able to make this "suppressive factor," and we've seen this in adults on AZT, as well. Going back to your first comment, I don't believe that the only "suppressive" mechanism has to do with a CD8 suppressor cell. There could be viral products, there could be cytokines that are a result of HIV infection-any or all of which could contribute to mechanisms of immune dysfunction or immune regulation that are independent of CD4-cell depletion.
Dr. Strober: Did you try to look at the CD4+ T cells from the various patients in culture? One idea that came to my mind was that if you could stimulate the CD4 cells with PHA (a stimulus that is relatively preserved), carry them in culture for several weeks after stimulation, and look for a response to either ALLO or REC, would you recover in culture what the patient presumably has lost in vivo?

Dr. Shearer: That is a question in which we have been very interested, and one that we have studied. Thus, we demonstrated that we could use ALLO plus FLU costimulation in vitro to reconstitute a cytotoxic T-cell response to influenza. In fact, we could activate HIV-specific cytolytic cells by costimulating with ALLO plus HIV peptides. This approach provides another potential approach for therapy, although one has to be concerned that overstimulation of the immune system might set the patient up for a number of activated cells that could be infected very efficiently by HIV. I am not sure that approach could be used therapeutically, but in vitro experiments of this type have been done and are in progress.

Dr. Yolken: Your data had very striking implications for the way we usually look at perinatal infections. Would you speculate on why you think the mothers and the babies respond to different peptides representing different HIV strains since presumably they are infected with the same strain? Do you think a certain subtype infects the baby, or do you think there is an HLA-dependent response to the peptides?

Dr. Shearer: In studying the HIV-specific responses of known seropositive adults, we have not found (by cytotoxic activity) any particular HLA class I epitope that was predominant in the response to these peptides. We do not know why the mother may respond to $\mathrm{T} 1$ and the baby to $\mathrm{T} 2$. Even within the same individual over time, our experience has been that one can see a predominant response to the T1 or T2 peptides, whereas if you rebleed the patient 6 mo later, the response may be stronger to p18 or to T4. So this variation in response seems to be dynamic, even within an individual. I cannot answer why that is the case, and certainly cannot answer why mother and baby would be different. We do know that at the time we draw the blood the mother can be responding to one peptide, while the baby can be responding to another. This point was used in my discussion to support the argument that, on an immunologic basis, the cord blood is not of maternal origin.

Dr. Levy: There is another explanation possible for the two children not responding to HIV antigens: that they were infected after birth. Obviously you need many more to study. It would be interesting to know whether the cord blood contained virus. I would predict it did not and these children were infected later on.

Dr. Shearer: Certainly, that is a possibility.

Dr. Wara: As a follow-up, do you know when the first positive culture was obtained on those two infants?

Dr. Shearer: One was detected at birth and the other was observed a few weeks after birth. This is a dynamic process, and the infants are being brought in repeatedly for retesting.

Dr. Wara: I would like to point out that many of us feel that a subset of infants is infected in utero. Those infants probably will have positive cord cultures, but the majority of infants we have seen who eventually prove to be infected have their first positive culture at about $8 \mathrm{wk}$ of age, their cord bloods are not positive, and their 2-wk cultures are not positive. Just by chance, you may have picked up two infants who were infected in utero. I agree with Dr. Levy that you need to expand your information, but it is very interesting.

Dr. Shearer: We are expanding our data base, both by longitudinal retesting of the infants already on study, and by including additional mother-infant pairs. 